\title{
Resource integration optimization of convenience service platforms adopting dynamic service modes in new retail
}

Yang Yang and Jianming Yao*

* Correspondence: jmyao@163.com Business School, Renmin University of China, Beijing 100872, China

\begin{abstract}
This paper analyzes the key issues of resource integration, and proposes a method for solving the problem of achieving efficient resource integration for convenience service platforms that adopt dynamic service modes. This method considers both the service level of collaborative resources under dynamic service modes, and collaborative resources' satisfaction of service modes in the resource integration. In addition, dominant factors needing the most attention during resource integration under dynamic service modes are excavated. Moreover, a model for resource integration optimization is established, and ant colony algorithm is used to solve the problem. Finally, a case is used to verify the feasibility of the method.
\end{abstract}

Keywords: Convenience service platforms, Dynamic service modes, Resource integration, Ant colony algorithm, Collaborative resources

\section{Introduction}

With the accelerating pace of life, customers are seeking further convenience of retail service. At present, convenience stores, a vital form of retail service, have been increasingly favored by consumers for their convenience, rapidity, and accessibility in an emergency. The presence of convenience stores has become an essential part of daily life (Sakashita 2000). The largest retail groups have developed new convenience stores, thus, the retail market share of convenience stores is rising (Gahinet and Cliquet 2018). Moreover, as novel modes, like new retail, which merges brick and mortar stores with ecommerce, are emerging (Wang and Li 2019), it is feasible for a large number of chain convenience stores to combine the multi-end scale effect and brand reputation with well-developed online operations to transform into convenience service platforms. For instance, a number of Freshippo supermarkets, flagships of Alibaba, have set up life service centers at which convenience services like laundry, hair salons and repairs can be found. Convenience Bee, a cashier-free convenience store, has also offered laundry services, covering the neighborhoods and business districts in the vicinity of its hundreds of stores. Suning Xiaodian, the convenience store of Chinese retailer

(c) The Author(s). 2021 Open Access This article is licensed under a Creative Commons Attribution 4.0 International License, which permits use, sharing, adaptation, distribution and reproduction in any medium or format, as long as you give appropriate credit to the original author(s) and the source, provide a link to the Creative Commons licence, and indicate if changes were made. The images or other third party material in this article are included in the article's Creative Commons licence, unless indicated otherwise in a credit line to the material. If material is not included in the article's Creative Commons licence and your intended use is not permitted by statutory regulation or exceeds the permitted use, you will need to obtain permission directly from the copyright holder. To view a copy of this licence, visit http://creativecommons.org/licenses/by/4.0/. 
Suning.com Co., now provides various life services, including housekeeping and home appliance cleaning. The general operational framework of convenience stores after transformation is demonstrated in Fig. 1.

As shown in Fig. 1, the center is a convenience service platform transformed from a convenience store that offers a variety of daily convenience service items, such as car washing and delivery services, to different customers $k(k=1,2, \ldots K)$. As a service integrator, convenience service platforms need to integrate appropriate service resources $r$ $(r=1,2, \ldots R)$ to provide these services.

For each service item $m(m=1,2, \ldots M)$, the convenience service platform can choose alternative service modes $n(n=1,2, \ldots N)$ to provide the services. On the one hand, different service modes offer different levels of convenience and cost; on the other hand, different service resources offer different service levels under different service modes and have respective preferences for different service modes given their own ability.

Apparently, the success of this platform depends on whether the integrated service resources can provide consumers with a satisfactory experience. To fulfill the goal, the core enterprise in charge of the platform is expected to integrate the service resources in an effective and reasonable manner. Resource integration is the process of effectively identifying, acquiring, and allocating external resources (Ma et al. 2019), and is a critical process for companies to maximize resource function (Lyu et al. 2019). In other words, the efficiency of resource integration determines the service capabilities of the convenience service platforms.

As services have received increasingly more attention, a large number of scholars have conducted research on service supply chain management in sectors such as outsourcing (e.g., Benjaafar et al. 2007; Lahiri et al. 2013), customer service (e.g., Al Hamadi et al. 2015; Hall and Porteus 2000), capacity management (e.g., Cao and Jiang 2013; Ching et al. 2011), and service competition (e.g., Shi et al. 2019; Wang et al. 2019). Industries such as telecommunications (e.g., Canakoglu and Bilgic 2007; Hasija et al. 2008), electricity (e.g., Oliveira et al. 2013) and logistics (e.g., Liu et al. 2013; Liu and Xie 2013; Liu et al. 2018) have also been examined.

However, the existing research is largely based on static service modes (including service time, delivery, and contents of service); they do not consider the dynamic changes

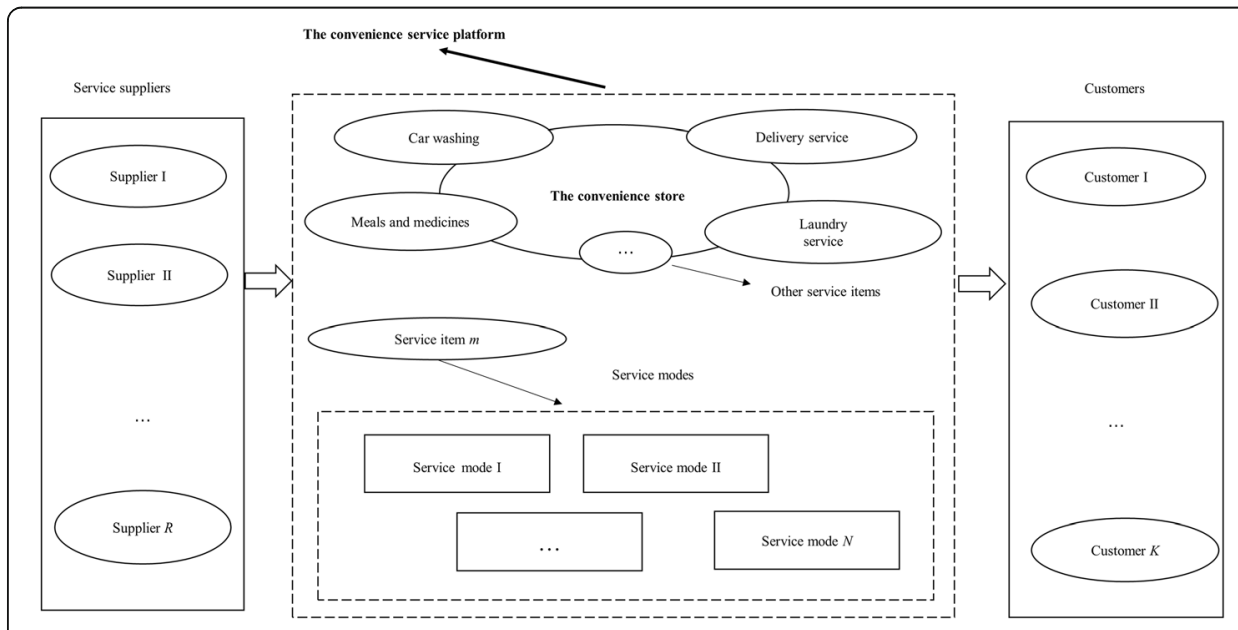

Fig. 1 Service form of convenience stores after transformation 
present in service modes. In reality, consumers' needs with regard to the convenience of services frequently vary with specific surroundings and scenarios. Therefore, in designing service items for convenience service platforms, it is advisable to consider how to meet consumers' changing needs through dynamic service modes and examine how resource integration can be incorporated. In other words, compared with the traditional single service mode, the influence of dynamic of service modes need to be considered in the resource integration for convenience service platforms. Therefore, this study is aimed at exploring the optimization of resource integration under dynamic service modes.

With the purpose of offering a method for resource integration optimization of convenience service platforms under dynamic service modes, the paper first analyzes the key issues of resource integration, and then establishes the optimization model. The ant colony algorithm is adopted to find the solution, and a case is analyzed to verify the feasibility of the model. The next section, Section 2, will review relevant literature in this aspect. Section 3 includes the description of dynamic service modes of convenience service platforms. Section 4 focuses on the excavation of key factors for resource integration under dynamic service modes. The optimization model of resource integration is established in Section 5, and the selection and adoption of the algorithm is demonstrated in Section 6. In Section 7, the feasibility of the model is verified through a case. Section 8 presents the conclusion.

\section{Literature review}

There exists a large amount of literature on the supply chain management of convenience stores, including studies on the location and delivery (e.g., Hübner et al. 2016; Sakashita 2000; Wood and Browne 2007), and research about replenishment and category management (e.g., Alftan et al. 2015; Han et al. 2014). As Chinese convenience stores are transforming and upgrading into convenience service platforms, it is necessary to take into account the issue of resource integration for service suppliers from the perspective of service operation management.

In addition, a large amount of research has been conducted on the selection and allocation of supply chain resources. In terms of resource integration in manufacturing, researchers have paid much attention to sustainable resource integration and the resource integration in the service-oriented transformation of manufacturing. Bastl et al. (2017) explore the role of the manufacturer-supplier relationship in service performance within service triads. Luthra et al. (2017) propose a framework for sustainable supplier selection and evaluation in supply chains. Lamba and Singh (2019) propose a dynamic supplier selection model considering the carbon emissions in a big data environment. Ayala et al. (2019) study the moderating role of service suppliers in product companies (servitization). With regard to the integration of service products, some scholars explored the resource selection and integration in third-party logistics service. Pamucar et al. (2019) provide a method for the assessment of a third-party logistics provider. Lyu et al. (2019) examine the impact of logistics platforms and location on logistics resource integration and operational performance.

However, despite thriving service products, research concerning the resource integration of the service sector is lacking. In particular, few consider the dynamic changes in service modes, though the importance of resource integration has become increasingly 
popular. Supply chain management has become an essential method in aiding enterprises to improve their operation flexibility and acquire external resources (Yao 2010; Yao and $\mathrm{Gu}$ 2014). Yao (2017) points out that a supply chain network comprises different supply chain resources, and its operation efficiency is determined by the level of supply chain resource integration. Companies can improve their operational performance and obtain competitive advantage through resource integration (Lyu et al. 2019). Therefore, in view of the importance of resource integration and the lack of research about the impact of dynamic service modes on resource integration, this research attempts to explore the optimization of service resource integration in terms of dynamic service modes.

The theoretical contributions of this paper are mainly the following.

Firstly, given that few studies consider the influence of different service modes in the process of resource integration with regard to the adoption of dynamic service modes, the present research question eliminates the existing gap as much as possible.

Secondly, the characteristics of resource integration under dynamic service modes are analyzed in this paper. Specifically, two aspects are considered, namely, service level difference of collaborative resources under different service modes, and collaborative resources' satisfaction toward different service modes. In addition, the key factors of resource integration under the dynamic service modes are excavated and analyzed.

Thirdly, the procedure of the proposed method is straightforward, and generally applicable to the optimization of resource integration of the convenience service platforms that adopt the dynamic service modes.

\section{Dynamic service modes of convenience service platforms}

Convenience service platforms provide convenience services against customer needs for convenience. Berry et al. (2002) define service convenience as a consumers' perception of minimized time and effort required to obtain a service. It is worth noting that the degree of customer demand for convenience is not constant and often changes with the surrounding environment and conditions. For example, the same customer's needs for convenience differ between weekdays and weekends, and also between peak work hours and noon; in addition, changes in the environment, such as weather and temperature, will also cause changes in customer convenience needs. Under the condition in which customers have insufficient time or energy, they pay more attention to the service convenience and factors that can reduce the time and energy expended instead of factors such as quality and price; conversely, under the condition in which customers have sufficient time or energy, they pay less attention to the service convenience and focus more on factors such as quality and price. However, the improvement of service convenience is often coupled with cost increases. Thus, convenience service platforms should supply suitable convenience based on the dynamic service convenience demand of customers.

Service convenience is a multidimensional construct, and should be understood within the context of the activities that consumers undergo in the process of purchasing and using a service (Colwell et al. 2008). Brown (1990) proposes five dimensions for the concept of convenience: time, place, acquisition, use, and execution. As the acquisition and use dimensions do not vary with service modes because they are influenced by the transaction channels and payment methods of convenience service platforms, in 
this research, we mainly focus on the time, place, and execution dimensions, which do vary with service modes. Taking a community convenience store with laundry services as an example, Table 1 shows different service details in terms of the different service dimensions that a convenience service platform can provide. The service contents chosen by a convenience service platform against the different dimensions constitute the whole service mode of that service item, as shown by the example in Table 2 . Obviously, the convenience levels of the service modes are different.

In reality, platforms generally cannot provide all the possible service modes for customers because too high a degree of customization in service modes cannot effectively produce economies of scale. Therefore, platforms need to select and design service modes based on target customers' convenience demand. As static service modes find it difficult to meet changing customer demand, the platforms often need to set up dynamic service modes.

For example, as shown in Fig. 2, a convenience service platform can use the combination of service modes (3) and (6) for customers to choose in a certain period (such as period $t$ ), and in another period (such as $t+1$ ), adopt the combination of service modes (2) and (4).

Convenience service platforms can divide the resource integration decision period into $T$ different stages according to the changes in customer convenience needs. Customers' desired service mode (obtained through a pilot survey) can be used at each stage. The selection ratio of each service mode during the entire resource integration decision period can then be obtained.

\section{Key issues of resource integration of convenience service platforms under dynamic service modes}

In this part, the procedures involved in resource integration under dynamic service modes are defined, and key factors in the integration process are discussed.

\section{Resource integration procedure under dynamic service modes}

As mentioned earlier, the key to the success of convenience service platforms is being able to match customer demand to the convenience experience, which relies on the effective and reasonable integration of service resources. However, the resource

Table 1 Examples of different service details provided by a convenience service platform by convenience dimensions

\begin{tabular}{|c|c|c|}
\hline Dimension & Service & \\
\hline \multirow[t]{2}{*}{$\begin{array}{l}\text { Place } \\
\text { convenience }\end{array}$} & $\begin{array}{l}\text { Self-service goods } \\
\text { delivery }\end{array}$ & $\begin{array}{l}\text { Customer delivers the clothes to be cleaned to the convenience store, } \\
\text { the laundry is taken away from the convenience store }\end{array}$ \\
\hline & $\begin{array}{l}\text { Door-to-door } \\
\text { goods pick-up }\end{array}$ & $\begin{array}{l}\text { Laundry is delivered to the customer's house directly, and the clothes to } \\
\text { be cleaned are collected }\end{array}$ \\
\hline \multirow[t]{2}{*}{$\begin{array}{l}\text { Time } \\
\text { convenience }\end{array}$} & $\begin{array}{l}\text { Standard service } \\
\text { time }\end{array}$ & Service is only available at specified times \\
\hline & $\begin{array}{l}\text { Flexible service } \\
\text { time }\end{array}$ & Service can be provided at any time preferred by the customers \\
\hline \multirow{2}{*}{$\begin{array}{l}\text { Execution } \\
\text { convenience }\end{array}$} & Routine procedure & Standardized laundry procedure \\
\hline & $\begin{array}{l}\text { Customized } \\
\text { service }\end{array}$ & $\begin{array}{l}\text { A series of individualized services, such as clothes bleaching, dying, } \\
\text { modifications, and maintenance, are added }\end{array}$ \\
\hline
\end{tabular}


Table 2 Example of the different service modes of a convenience service platform with laundry service

\begin{tabular}{|c|c|c|c|c|}
\hline Service mode 1 & Service mode 2 & Service mode 3 & $\ldots$ & Service mode $n$ \\
\hline $\begin{array}{l}\text { Self-service goods } \\
\text { delivery + Standard } \\
\text { service time + Routine } \\
\text { procedure }\end{array}$ & $\begin{array}{l}\text { Door-to-door goods } \\
\text { pick-up + Flexible service } \\
\text { time + Routine } \\
\text { procedure }\end{array}$ & $\begin{array}{l}\text { Door-to-door goods pick- } \\
\text { up }+ \text { Standard service } \\
\text { time + Customized } \\
\text { service }\end{array}$ & $\ldots$ & $\begin{array}{l}\text { Door-to-door goods } \\
\text { pick-up + Flexible service } \\
\text { time + Customized } \\
\text { service }\end{array}$ \\
\hline
\end{tabular}

integration process of convenience service platforms based on different convenience service modes is a typical dynamic process with different characteristics. Therefore, the service resource integration of convenience service platforms should be different from that adopted by static service modes. The resource integration process based on dynamic service modes is described in Fig. 3.

As shown in Fig. 3, when convenience service platforms under dynamic service modes integrate resources, they must first clarify their adoption of the different service modes using a dynamic decision-making process. The decision-making period for the resource integration can be divided into different stages according to the changes in customers' convenience demand. For each delimited stage, convenience service platforms select one or two service modes to match customer demand; thus, the convenience service platforms can determine the adoption of service modes during the decision-making period of resource integration.

The evaluation of collaborative resources is more complicated when convenience service platforms adopt dynamic service modes than when they adopt static service modes. Specifically, two aspects need to be considered, namely, service level difference of collaborative resource under the different service modes, and collaborative resources' satisfaction toward different service modes. In addition, not all the resource features can be considered when integrating resources, so those needing the most attention should be clarified. Therefore, convenience service platforms need to excavate the dominant factors for resource integration based on dynamic service modes, and carry out resource integration in a focused and targeted manner. Convenience service platforms under dynamic service modes should comprehensively consider the above aspects to optimize resource integration.

\section{Collaborative resources' service level under dynamic service modes}

This article assumes that convenience service platforms are only responsible for facilitating transactions, other service steps are completed by their carried service resources,

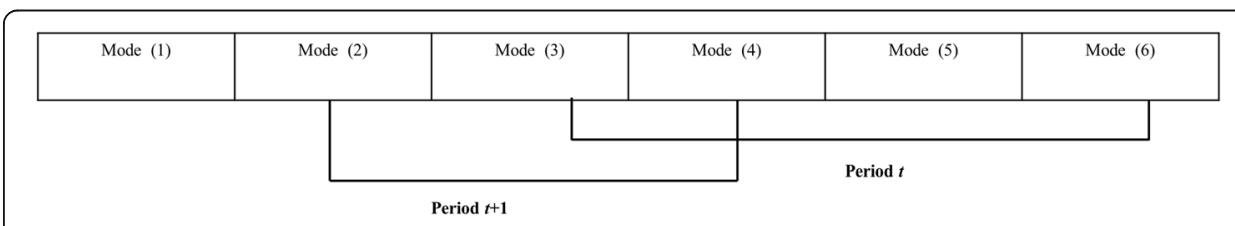

Fig. 2 Sketch of dynamic service modes of convenience service platforms 


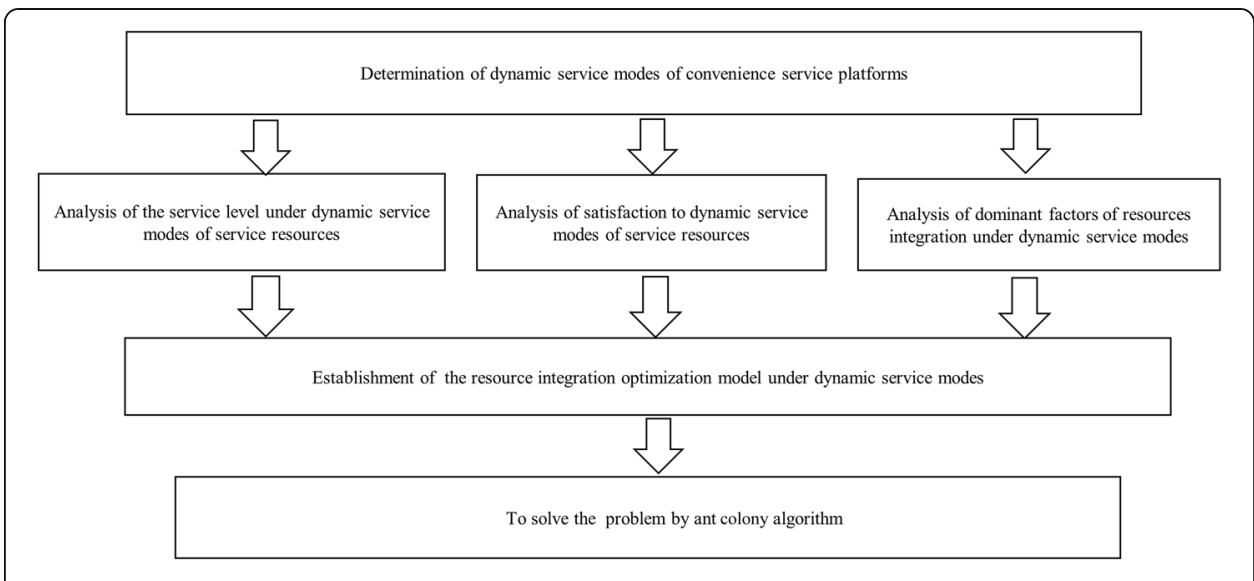

Fig. 3 Flow chart of resource integration of convenience service platforms under dynamic service modes

and each carried resource can cooperate with platforms to utilize different service modes for the service. It is worth noting that different service resources have different service levels under different service modes, given their own ability. For example, the service supplier's logistical speed will affect its service level when the door-to-door delivery mode is adopted, and the service provider's capability for providing customized services will affect its service level when the customized service mode is adopted. This leads to changes in the service level of collaborative resources when convenience service platforms adopt different service modes, so the evaluation of collaborative resources' service level should be considered in combination with dynamic service modes.

Considering that customers may have different expectations toward service performance for different service modes, and that perceived service levels are influenced by the (dis)confirmation of expected service performance (Bolton and Drew 1991; Oliver 1977; Rust et al. 1999; Szymanski and Henard 2001), the customer perceived value, instead of the objective value, should be used to reflect the service level of suppliers under different service modes. In line with prospect theory (Kahneman and Tversky 1979) which believes people derive utility from gains and losses, measured relative to the reference point, rather than from the absolute levels of wealth and are more sensitive to losses than to gains of the same magnitude, we take the customer expectation of service level as the reference point to calculate their perceived value. If the performance of the actual service exceeds customer expectations, gain is appreciated, and the perceived value increases; if the performance of the actual service is lower than that of customer expectations, loss is appreciated, and the perceived value decreases.

According to the value function of prospect theory, when describing the customer perceived value, we assume that, under the service mode $A_{m n}, f_{m n}$ is the $f^{\text {th }}$ index affecting the service level, the customer expectation for service performance with the index $f_{m n}$ is $l_{f m n}$, and the actual performance of collaboration resource $i$ is $l_{f(m n) i}$. According to the value function in prospect theory, the formula for the customer perceived value $v_{f(m n) i}$ of $l_{f(m n) i}$ relative to $l_{f m n}$ is : 


$$
v_{f(m n) i}=\left\{\begin{array}{c}
\left(l_{f(m n) i}-l_{f m n}\right)^{\alpha}, l_{f(m n) i} \geq l_{f m n} \\
-\theta\left(l_{f m n}-l_{f(m n) i}\right)^{\beta}, l_{f(m n) i}<l_{f m n}
\end{array},\right.
$$

where $\alpha$ and $\beta$ respectively represent the concave-convex degree of the gain and loss value functions as perceived by the customer. As customers are more sensitive to loss than gain, $\theta>1$. Through the experimental tests and data regression analysis on a large number of decision-making individuals, Tversky and Kahneman (1992) conclude that $\alpha=\beta=0.88$ and $\theta=2.25$, which are the parameter values that can approximately indicate the behavioral preferences of the decision-maker. Therefore, this article takes the above values as the parameters.

Assume that the importance attached by customers to the index $f_{(m n)}$ is $W_{f(m n)}$, then, under the service mode $A_{m n}$ adopted by the convenience service platform, the customer perceived value about the service level of the collaborative resource $i, E_{(m n) i}$, can be expressed as:

$$
E_{(m n) i}=\sum_{f=1}^{F} W_{f(m n)} v_{f(m n) i} .
$$

Combined with $u_{m n}$, the proportion of each service mode utilized by convenience service platforms during the decision-making stage of resource integration, the customers' overall perceived value of the collaborative resource $i$ under dynamic service modes can be expressed as:

$$
E_{m i}=\sum_{n=1}^{N}\left[u_{m n}\left(\sum_{f=1}^{F} W_{f(m n)} v_{f(m n) i}\right)\right]
$$

\section{Collaborative resources' satisfaction about dynamic service modes}

Because different resource individuals have different resource features, their service and coordination costs under different service modes are also different; they have respective preferences for different service modes. When an unsuitable service mode for the collaborative resource is utilized too much, the willingness of the collaboration resource to cooperate with the platform will be reduced-this is not conducive to the long-term cooperation of both sides. Therefore, collaborative resources' preferences toward different service modes need to be considered when convenience service platforms adopting dynamic service modes carry out resource integration. It is thus necessary to describe collaborative resources' relative satisfaction under different service modes.

The approach we utilized in this article allows collaborative resources to first sequence their preferences toward various service modes based on their own resource features. Suppose, for the service item $m$, the preference sequence value set of the collaborative resource $i$ toward the service mode $A_{m n}$ is $R_{i}=\left\{R_{i n}^{1}, R_{i n}^{2}, \ldots R_{i n}^{N}\right\}$, in which $R_{i n}^{k}$ is the ranking the collaborative resource $i$ gives to the mode $A_{m n}$, the smaller the sequence number is, the bigger the satisfaction of the collaborative resource $i$ toward the service mode $A_{m n}$. Suppose the satisfaction of the collaborative resource $i$ toward the service mode $A_{m n}$ is $S_{i(m n)}$, there are many describing patterns about the relationship between $S_{i(m n)}$ and $R_{i n}^{k}$. This article adopts $S_{i(m n)}=1 / R_{i n}^{k}$ to describe their relationship, 
thus $S_{m i}$, the overall satisfaction of the collaborative resource $i$ toward dynamic service modes, can be expressed as:

$$
S_{m i}=\sum_{n=1}^{N}\left(u_{m n} S_{i(m n)}\right) .
$$

\section{Excavation of key factors of resource integration under dynamic service modes}

Before making decisions for resource integration, it is necessary to evaluate a large number of optional resources, identify the most suitable resources for integration, and develop long-term strategic cooperation with suitable resources. If taking the efficiency of resource integration into consideration, platforms cannot evaluate all the aspects of optional resources when analyzing their value and evaluating their performance. Instead, they should combine the features of the platforms' dynamic service modes, evaluate optional resources with emphasis, clarify the features needing the most attention when conducting resource integration, that is, the key factors needing the most attention when conducting resource integration, and carefully check the performance of optional resources in these characteristic aspects, then use them as the standard for supplier resource integration.

It is worth noting that when platforms choose different service modes, the impact of the various resource characteristics on the service level will change. For example, when the service mode contains speed service contents, the logistic speed and information interaction capability of the service supply resources will have a great impact on the service level, and if the service mode includes customized service contents, the customized service capabilities of the collaborative resources will have a great impact on the service level. Based on this, Table 3 shows the excavated dominant factors to which more attention needs to be paid when integrating resources under dynamic service modes.

$V_{m n}$ in Table 3 indicates the correlation between the characteristics of optional resources and the service level under different service modes; we can assign values to $V_{m n}\left(0 \leq V_{m n} \leq 1\right)$ as per actual correlation conditions. Combined with the ratio of each service mode under dynamic service modes, we can obtain various factors' overall degree of concern $e_{i}$ during the resource integration of convenience service platforms. As mentioned above, when integrating individual resources, we need to carry out targeted investigations on specific aspects of resource performance. Therefore, we can set a certain standard for $e_{i}$, for example, set the factors with $e_{i}$ greater than 0.45 as the key

Table 3 Excavation for dominant factors of resource integration of convenience service platforms under dynamic service modes

\begin{tabular}{lllllll}
\hline & & & \multicolumn{5}{l}{ Factors of selectable individual resource } \\
\cline { 3 - 7 } Mode ratio & Service mode & Service level & Factor $\mathbf{1}$ & Factor $\mathbf{2}$ & $\ldots$ & Factor $\boldsymbol{m}$ \\
\hline$u_{1}$ & $\mathrm{~A}_{1}$ & $P_{1}$ & $V_{11}$ & $V_{21}$ & $\ldots$ & $V_{m 1}$ \\
$u_{2}$ & $\mathrm{~A}_{2}$ & $V_{21}$ & $V_{22}$ & $\ldots$ & $V_{m 2}$ \\
$\ldots$ & $\ldots$ & $\ldots$ & $\ldots$ & $\ldots$ & $\ldots$ \\
$u_{n}$ & $\ldots$ & $\mathrm{A}_{n}$ & $V_{n 1}$ & $V_{n 2}$ & $\ldots$ & $V_{m n}$ \\
\multicolumn{2}{l}{ Overall degree of concern for factors } & $e_{1}$ & $e_{2}$ & $\ldots$ & $e_{i}$ \\
\hline
\end{tabular}


factors to which more attention needs to be paid when integrating resources, and evaluate the performance of resources on this basis.

\section{Resource integration optimization model}

The optimization model of resource integration under dynamic service modes is established in this section.

As platforms carrying service items, convenience service platforms need to consider the interests of both customers and service suppliers. Hence, during resource integration, we need to consider the customer perceived value of service level on one hand and suppliers' satisfaction toward dynamic service modes on the other. Therefore, this article sets four resource integration optimization objectives under dynamic service modes: maximization of customer perceived value of service level; maximization of suppliers' satisfaction toward dynamic service modes; minimization of resource integration cost; and minimization of resource integration time. To achieve the synthesis of the multiple optimization objectives, the parameters in the objective functions need to first be standardized. The parameters and variables of the optimization objectives are defined in Table 4.

The optimized model for resource integration is established as follows:

$$
\begin{aligned}
\max Z_{1} & =\max \sum_{m=1}^{M} \sum_{i=1}^{I} E_{r m i} g\left(r_{m i}\right), \\
\max Z_{2} & =\max \sum_{m=1}^{M} \sum_{i=1}^{I} S_{r m i} g\left(r_{m i}\right), \\
\min Z_{3} & =\min \sum_{m=1}^{M} \sum_{i=1}^{I} C_{m i} g\left(r_{m i}\right), \\
\min Z_{4} & =\min \sum_{m=1}^{M} \sum_{i=1}^{I} T_{a(m i)} g\left(r_{m i}\right),
\end{aligned}
$$

subject to

$$
\begin{aligned}
& L^{*}{ }_{k m i}=L_{k m i}+X_{k m i} C_{k m i} . \\
& C_{m i} \leq C_{\text {max }} . \\
& \left|T_{m}-\left(T_{\text {end }(m i)}-T_{s t a(m i)}\right)\right| \leq T_{s(m)} .
\end{aligned}
$$

Eqs. (5)-(8) respectively represent the four optimization objective functions for resource integration. Eq. (9) is the relation constraint between the improvement amount of resource-dominant factors' operation level and the cost input in resource integration. Eq. (10) is the cost constraint of the resource integration input, and ensures the cost of individual resource integration is not higher than the maximum integration cost the convenience service platforms can accept for individual resources. Eq. (11) is the time constraint in resource integration, and ensures the integration time discrepancy when integrating individual resources is not greater than the maximum time discrepancy the convenience service platforms can accept.

\section{Algorithm}

The optimization model of resource integration under dynamic service modes is essentially a problem of constrained multi-objective optimization that requires a trade-off 
Table 4 Description of various parameters and variables

\begin{tabular}{|c|c|}
\hline Notation & Description \\
\hline M & Number of service items carried by convenience store \\
\hline$m$ & Index of each service item \\
\hline$A_{m n}$ & Index of different service modes of each service item provided by convenience store \\
\hline Im & $\begin{array}{l}\text { For service item } m \text {, the total number of individual resources selectable for convenience store's } \\
\text { resource integration }\end{array}$ \\
\hline$r_{m i}$ & Index of each selectable individual resource \\
\hline$f_{m n}$ & $\begin{array}{l}\text { The number } f \text { evaluation index utilized by customers to evaluate suppliers' service level under the } \\
\text { service mode } A_{m n}\end{array}$ \\
\hline$W_{f m n}$ & The degree of concern customers attached to the index $f_{m n}$ \\
\hline$E_{r(m n) i}$ & Customer's perceived value of service level of supplier $r_{m i}$ under the service mode $A_{m n}$ \\
\hline$u_{m n}$ & $\begin{array}{l}\text { The ratio of service mode } A_{m n} \text { adopted by convenience service platforms under dynamic service } \\
\text { modes }\end{array}$ \\
\hline Ermi & The overall customers' perceived value of service level of supplier $r_{m i}$ under dynamic service modes \\
\hline Srmni & Satisfaction of collaborative resource $r_{m i}$ toward the service mode $A_{m n}$ \\
\hline$S_{r m i}$ & The overall satisfaction of collaborative resource $r_{m i}$ toward dynamic service modes \\
\hline$K_{m}$ & $\begin{array}{l}\text { For service item } m \text {, the number of dominant factors of convenience service platforms' resource } \\
\text { integration under dynamic service modes }\end{array}$ \\
\hline$k_{m}$ & $\begin{array}{l}\text { For service item } m \text {, the index of dominant factors of convenience service platforms' resource } \\
\text { integration under dynamic service modes }\end{array}$ \\
\hline$T_{m}$ & For service item $m$, the expected input time during individual resource integration \\
\hline$T_{\text {sta }(m i)}$ & Starting time to integrate resource $r_{m i}$ \\
\hline$T_{\text {end }(m i)}$ & Finishing time to integrate resource $r_{m i}$ \\
\hline$T_{a(m i)}$ & The actual time used to integrate resource $r_{m i} T_{a(m i)}=T_{\text {end }(m i)}-T_{\text {sta(mi) }}$ \\
\hline$T_{s(m)}$ & Tolerable time discrepancy during individual resource integration \\
\hline$C_{k m i}$ & The cost input to improve the dominant factor $k_{m}$ during the integration of resource $r_{m i}$ \\
\hline$L_{k m i}$ & The operation level of the dominant factor $k_{m}$ before the integration of resource $r_{m i}$ \\
\hline$X_{k m i}$ & $\begin{array}{l}\text { The improvement amount of the dominant factor } k_{m} \text { brought by the unit cost input during the } \\
\text { integration of resource } r_{m i}\end{array}$ \\
\hline$L^{*}{ }_{k m i}$ & The operation level of the dominant factor $k_{m}$ after the integration of resource $r_{m i}$ \\
\hline$C_{m i}$ & The overall cost input for the integration of resource $r_{m i}$ under dynamic service modes \\
\hline$C_{\max }$ & $\begin{array}{l}\text { The maximum integration cost allowed by convenience service platform to spend on individual } \\
\text { resource integration }\end{array}$ \\
\hline$g\left(r_{m i}\right)$ & A decision variable; $g\left(r_{m i}\right)=1$ if resource $r_{m i}$ is chosen as a integration object, otherwise, $g\left(r_{m i}\right)=0$ \\
\hline
\end{tabular}

between multidimensional optimization goals, thereby making it a nondeterministic polynomial time-hard problem. The ant colony algorithm is well-recognized for its strengths, like portability and high global convergence rate, in dealing with constrained multi-target modeling (Tang et al. 2013; Yao 2013; Yao and Deng 2015), and is widely applied in dynamic multi-target optimization problems (Panicker et al. 2013; Tang et al. 2013; Ting and Chen 2013; Wong et al. 2012; Yao 2010; Yao 2013).

Additionally, in this study, the four objective functions are probably correlated in a complex, nonlinear or contradictory manner, therefore, a dynamic weighing mechanism is needed. To solve the problem, the algorithm is supposed to meet two requirements. First, the decision variable should be of multiple attributes so that characteristics of different optimization targets can be simultaneously considered in the convergence of multiple targets. Second, the algorithm should be employed to cover all potential service resources instead of being confined to specific resources to better adapt to the complex or 
contradictive relationships among optimization objectives. Some available literature has compared ant colony algorithm with others for multi-objective optimization problems, and the former seems suitable given its characteristics (Dong et al. 2007; Merkle et al. 2002; Xiao et al. 2011). Thus, the ant algorithm is employed for this study.

When constructing the algorithm, each alternative service resource is considered as an independent unit with stable operational parameters. Suppose that the service resources network for the convenience service platforms is composed of source nodes, including those to be integrated. The selection process of resources to integrate corresponds to the foraging behavior of ants. Starting from the source to the object node, ants will move through the resource nodes in the network then disappear, and those alternative resources that do not meet the constraint conditions of the model are set as forbidden nodes. The nodes on the foraging path of ants are the selected ones for resource integration. According to different optimization objectives, the attraction probability of each resource node to ants is set as follows.

Set the attraction probability of $r_{m i}$ to the ants according to rule of the maximization of overall customer perceived value of resources' service level. Set $\pi_{e m i}$, the sort of pheromone quantities remain by ants passing $r_{m i}$, is the ratio of overall customer perceived value of resources' service level. Thus, the attraction probability is given as Eq. (12):

$$
P_{e}=\Pi_{e m i} / \sum_{i=1}^{I} \Pi_{e m i}
$$

Set the attraction probability of $r_{m i}$ to the ants according to rule of the maximization of suppliers' satisfaction with dynamic service modes. Set $\pi_{\text {smi }}$, the sort of pheromone quantities remain by ants passing $r_{m i}$, is the ratio of the suppliers' satisfaction with dynamic service modes. Thus, the attraction probability is given as Eq. (13):

$$
P_{s}=\Pi_{s m i} / \sum_{i=1}^{I} \Pi_{s m i}
$$

Set the attraction probability of $r_{m i}$ to the ants according to rule of the minimization of resource integration cost. Set $\pi_{c m i}$, the sort of pheromone quantities remain by ants passing $r_{m i}$, is the inverse ratio of the resource integration cost. Thus, the attraction probability is given as Eq. (14):

$$
P_{c}=\Pi_{c m i} / \sum_{i=1}^{I} \Pi_{c m i}
$$

Set the attraction probability of $r_{m i}$ to the ants according to rule of the minimization of resource integration time. Set $\pi_{t m i}$, the sort of pheromone quantities remain by ants passing $r_{m i}$, is the inverse ratio of the resource integration time. Thus, the attraction probability is given as Eq. (15):

$$
P_{t}=\Pi_{t m i} / \sum_{i=1}^{I} \Pi_{t m i}
$$

According to the above analysis, the comprehensive attraction probability of $r_{m i}$ for the ants is given in Eq. (16), where $\lambda_{1}, \lambda_{2}, \lambda_{3}, \lambda_{4}\left(0<\lambda_{1}, \lambda_{2}, \lambda_{3}, \lambda_{4}<1 ; \lambda_{1}+\lambda_{2}+\lambda_{3}+\lambda_{4}=\right.$ 
1) are the parameters that reflect the relative weight of the optimization objectives of the resource integration that are regulable upon actual scenes.

$$
P=\lambda_{1} P_{e}+\lambda_{2} P_{s}+\lambda_{3} P_{c}+\lambda_{4} P_{t}
$$

\section{Application case}

Convenience Store A is located near a large residential area, which is densely populated and has a high demand for daily convenience services. Due to the high commercial rent, there are few stores that offer such services as laundry and home appliance maintenance. Residents in this area are thus suffering from inconvenience. To attract customers, Convenience Store A plans to transform and upgrade into a convenience service platform, Convenience Service Platform A, and offer a variety of service items that provide convenience services to customers. In addition, dynamic service modes will be adopted for each convenience service based on customers' different needs at different stages.

Taking the laundry service as an example, Convenience Store A designs four service modes, as shown in Table 5, and will choose different modes based on customer needs at different stages.

Based on the above analysis of resource integration process, Convenience Store A takes the following steps when integrating collaborative resources of providing a laundry service:

(1) Confirm the dynamic service modes in the process of resource integration.

Convenience Store A can divide the resource integration decision period into $T$ different stages according to the changing customer convenience needs, and adopt the service mode desired most (obtained through a pilot survey) at each stage. Then, $u_{m n}$, the selection ratio of each service mode during the entire resource integration decision period, can be obtained.

(2) Excavate the key factors of resource integration. After setting the proportion of each service mode, the key factors of resource integration need to be outlined. Table 6 shows the excavation of the key factors of resource integration based on dynamic service modes of Convenience Store A.

(3) After confirming the proportion of each service mode and excavating the key factors of resource integration, Convenience Store A needs to pay attention to the service level of selectable individual resources under different modes. Based on the market survey and negotiation, Convenience Store A initially selected four laundry service suppliers: SUP1, SUP2, SUP3, and SUP4. Combined with the above-mentioned $u_{m n}$, we can calculate customers' comprehensive perceived value of service level of the selectable individual resources under the dynamic service modes according to prospect theory. First, Convenience Store A obtains customer expectation of the service level under different

Table 5 Service modes to be adopted by Convenience Store A on laundry service

\begin{tabular}{llll}
\hline Service mode $\mathbf{1}$ & Service mode $\mathbf{2}$ & Service mode $\mathbf{3}$ & Service mode $\mathbf{4}$ \\
\hline Self-delivery + Standard & Self-delivery + flexible & Door-to-door delivery + & Door-to-door delivery + \\
service time + Routine & service time + Routine & Standard service time + & flexible service time + \\
procedure & procedure & Customized service & Customized service \\
\hline
\end{tabular}


Table 6 Excavation of key factors of resource integration based on dynamic service modes

\begin{tabular}{|c|c|c|c|c|c|c|c|c|}
\hline \multirow[b]{2}{*}{$\begin{array}{l}\text { Modes } \\
\text { ratio }\end{array}$} & \multirow[b]{2}{*}{$\begin{array}{l}\text { Service } \\
\text { modes }\end{array}$} & \multirow[b]{2}{*}{$\begin{array}{l}\text { Weight of } \\
\text { indicators }\end{array}$} & \multirow[b]{2}{*}{$\begin{array}{l}\text { Indicators for service } \\
\text { level }\end{array}$} & \multicolumn{5}{|c|}{ Factors of selectable individual resource } \\
\hline & & & & $L_{\log }$ & $L_{\text {inf }}$ & $L_{\text {cul }}$ & $L_{\text {eme }}$ & $L_{\text {cus }}$ \\
\hline \multirow[t]{2}{*}{0.2} & $\mathrm{~A} 1$ & 0.6 & Service quality & 0.30 & 0.50 & 0.40 & 0.30 & 0.20 \\
\hline & & 0.4 & Service punctuality & 0.70 & 0.60 & 0.20 & 0.30 & 0.20 \\
\hline \multirow[t]{2}{*}{0.4} & $A 2$ & 0.4 & Service quality & 0.30 & 0.55 & 0.50 & 0.75 & 0.20 \\
\hline & & 0.6 & Service punctuality & 0.80 & 0.70 & 0.35 & 0.70 & 0.20 \\
\hline \multirow[t]{2}{*}{0.3} & A3 & 0.5 & Service quality & 0.10 & 0.75 & 0.50 & 0.20 & 0.80 \\
\hline & & 0.5 & Service punctuality & 0.70 & 0.80 & 0.30 & 0.25 & 0.90 \\
\hline \multirow[t]{2}{*}{0.1} & A4 & 0.7 & Service quality & 0.25 & 0.70 & 0.70 & 0.85 & 0.90 \\
\hline & & 0.3 & Service punctuality & 0.80 & 0.85 & 0.25 & 0.85 & 0.95 \\
\hline \multicolumn{4}{|c|}{ The comprehensive importance of each factor } & 0.49 & 0.67 & 0.40 & 0.50 & 0.47 \\
\hline \multicolumn{4}{|c|}{ The threshold for being a key factor } & 0.45 & & & & \\
\hline \multicolumn{4}{|c|}{ Being a key factor or not } & Yes & Yes & No & Yes & Yes \\
\hline
\end{tabular}

Notes. $L_{\log }$ stands for the performance of logistics; $L_{\text {inf }}$ for the degree of informatization; $L_{c u l}$ for the culture development of employees; $L_{e m e}$ for the ability to deal with an emergency; and $L_{\text {cus }}$ for the customization ability

modes according to a prior survey, and then calculates customers' comprehensive perceived value of the service level of the selectable individual resources.

(4) Confirm the collaborative resources' satisfaction of dynamic service modes.

Convenience Store A needs to request all collaborative laundry service resources to rank different service modes according to their own preferences. The lower the order value, the better the service mode is for the collaborative resources. The rankings are shown in Table 7.

As mentioned in the Section 4.3, when $R_{i n}^{k}$ is set to the ranking that the collaborative resource $i$ gives to the mode $A_{m n}$, this article adopts $S_{i(m n)}=1 / R_{i n}^{k}$ to describe the relationship between the ranking and satisfaction of the collaborative resource $i$ toward the service mode. Thus, the preference ranking of the above alternative collaborative resources for the different service modes is transformed into the satisfaction of the different service modes, as indicated in Table 8 .

(5) Combined with the above information, Table 9 shows a summary of alternative laundry services. The values have been normalized, and their units removed.

Based on the above information, Matlab is used to create a simulation. As the value of time discrepancy of SUP4's integration and cost are both higher than those the convenience service platform can accept, it will not be considered by the algorithm.

Table 7 Preference ranking of alternative service suppliers for different service modes

\begin{tabular}{lllll}
\hline & A1 & A2 & A3 & A4 \\
\hline SUP1 & 4 & 2 & 1 & 3 \\
SUP2 & 3 & 1 & 2 & 4 \\
SUP3 & 4 & 2 & 3 & 1 \\
SUP4 & 3 & 4 & 2 & 1 \\
\hline
\end{tabular}


Table 8 Satisfaction of alternative laundry service suppliers with dynamic service modes

\begin{tabular}{|c|c|c|c|c|c|}
\hline \multirow[t]{2}{*}{ Ratio of modes } & \multirow[t]{2}{*}{ Service modes } & SUP1 & SUP2 & SUP3 & SUP4 \\
\hline & & \multicolumn{4}{|c|}{ Satisfaction with the service modes } \\
\hline 0.2 & $\mathrm{~A} 1$ & 0.25 & 0.33 & 0.25 & 0.33 \\
\hline 0.4 & $\mathrm{~A} 2$ & 0.5 & 1 & 0.5 & 0.25 \\
\hline 0.3 & A3 & 1 & 0.5 & 0.33 & 0.5 \\
\hline 0.1 & A4 & 0.33 & 0.25 & 1 & 1 \\
\hline \multicolumn{2}{|c|}{ Suppliers' overall satisfaction with dynamic service modes } & 0.58 & 0.64 & 0.45 & 0.42 \\
\hline
\end{tabular}

Resource integration optimization of Convenience Store A should be considered in combination with the stages of its enterprise life. The focus of optimization objectives differs for the convenience service platform at different stages. In this paper, the startup stage, growth stage, and maturity stage are discussed, respectively. When Convenience Store A is in the start-up stage, the main aim of the convenience service platform is to increase its attraction to customers as well as boost the integration dimension, so it will pay more attention to the service level and the integration time; thus, the optimization parameters are set at $\lambda_{1}=0.30, \lambda_{2}=0.20, \lambda_{3}=0.10, \lambda_{4}=0.40$. The algorithm convergence results when the ant number is set at 300, and the operation batches at 300 are shown in Fig. 4. Based on the trend of ant convergence, SUP2 draws more attention when it is stable, indicating that alternative SUP2 offers more advantages for Convenience Store A than other laundry service suppliers do.

When Convenience Store A has completed the transformation into a convenience service platform and enters the growth stage, it will focus on balancing the benefit of customers and suppliers; thus, the optimization parameters are set at $\lambda_{1}=0.30, \lambda_{2}=$ $0.30, \lambda_{3}=0.20, \lambda_{4}=0.20$, and the algorithm convergence results are shown in Fig. 5. According to Fig. 5, SUP2 still enjoys an advantage at this stage.

When Convenience Service Platform A enters the maturity stage of development, customer stickiness and its negotiation ability with suppliers increase. It, thus, puts more focus on controlling integration cost and integration time; thus, the optimization parameters are set at $\lambda_{1}=0.15, \lambda_{2}=0.15, \lambda_{3}=0.40, \lambda_{4}=0.30$, and the algorithm convergence results are shown in Fig. 6. According to Fig. 6, SUP1 has the most attraction when the ants are in the stable condition, revealing that alternative SUP1 meets its need at this stage.

We found through this case that the convenience service platforms may place different emphases on their optimization goals at different stages, and, therefore, set the

Table 9 A summary of alternative laundry services

\begin{tabular}{lllll}
\hline & SUP1 & SUP2 & SUP3 & SUP4 \\
\hline Customers' overall perceived value of service level under dynamic service modes & 0.21 & 0.24 & 0.26 & 0.29 \\
Suppliers' overall satisfaction with dynamic service modes & 0.28 & 0.31 & 0.22 & 0.20 \\
Suppliers' integration cost & 0.60 & 0.75 & 0.80 & 0.85 \\
Maximum integration cost allowed for individual resource & 0.83 & & & \\
Integration time of each selectable individual resource & 0.58 & 0.62 & 0.57 & 0.68 \\
Expected integration time for individual resource & 0.60 & & \\
Time discrepancy of suppliers' resource integration & 0.02 & 0.02 & 0.03 & 0.08 \\
Tolerable time discrepancy during individual resource integration & 0.05 & & & \\
\hline
\end{tabular}




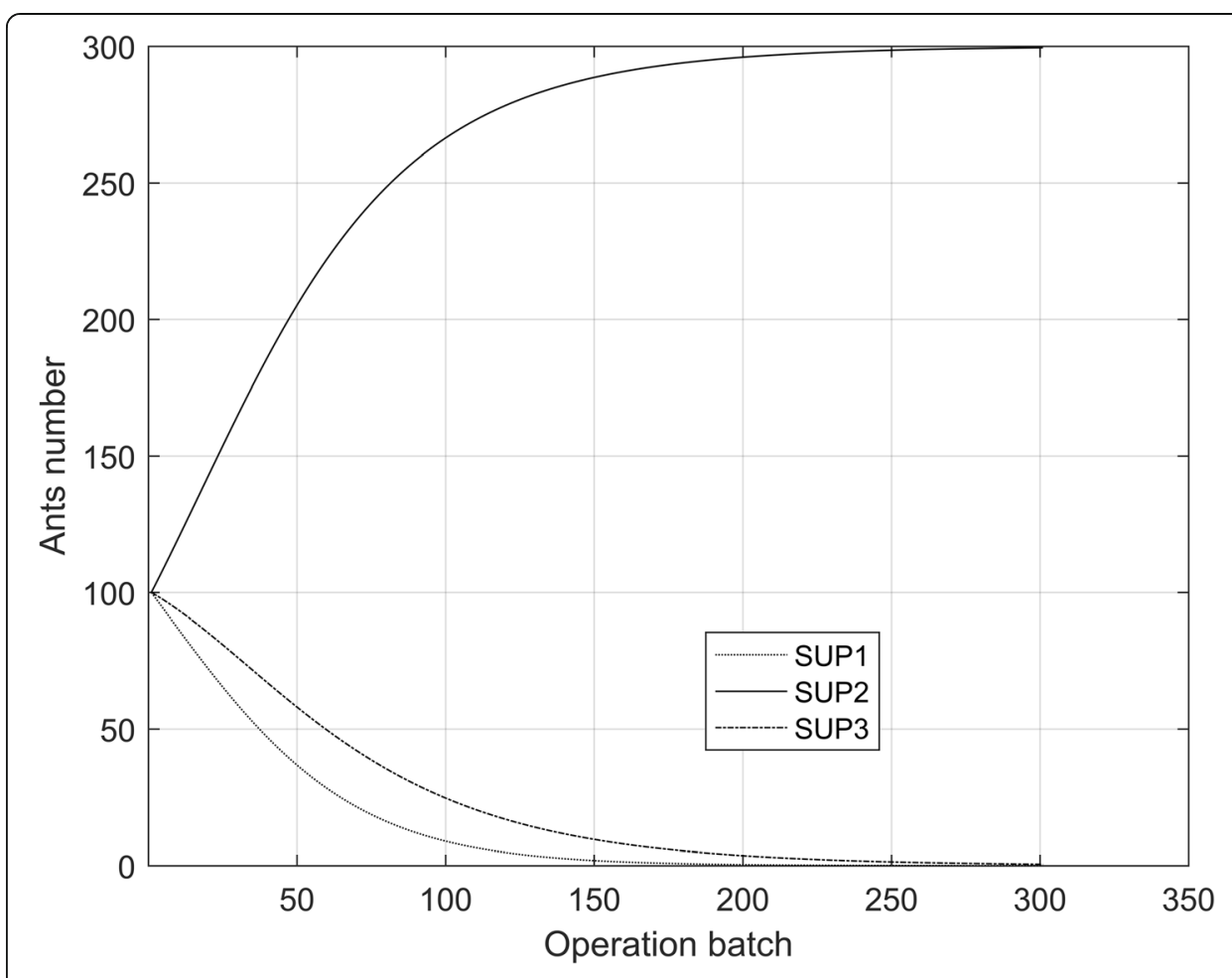

Fig. 4 Convergence results (start-up stage)

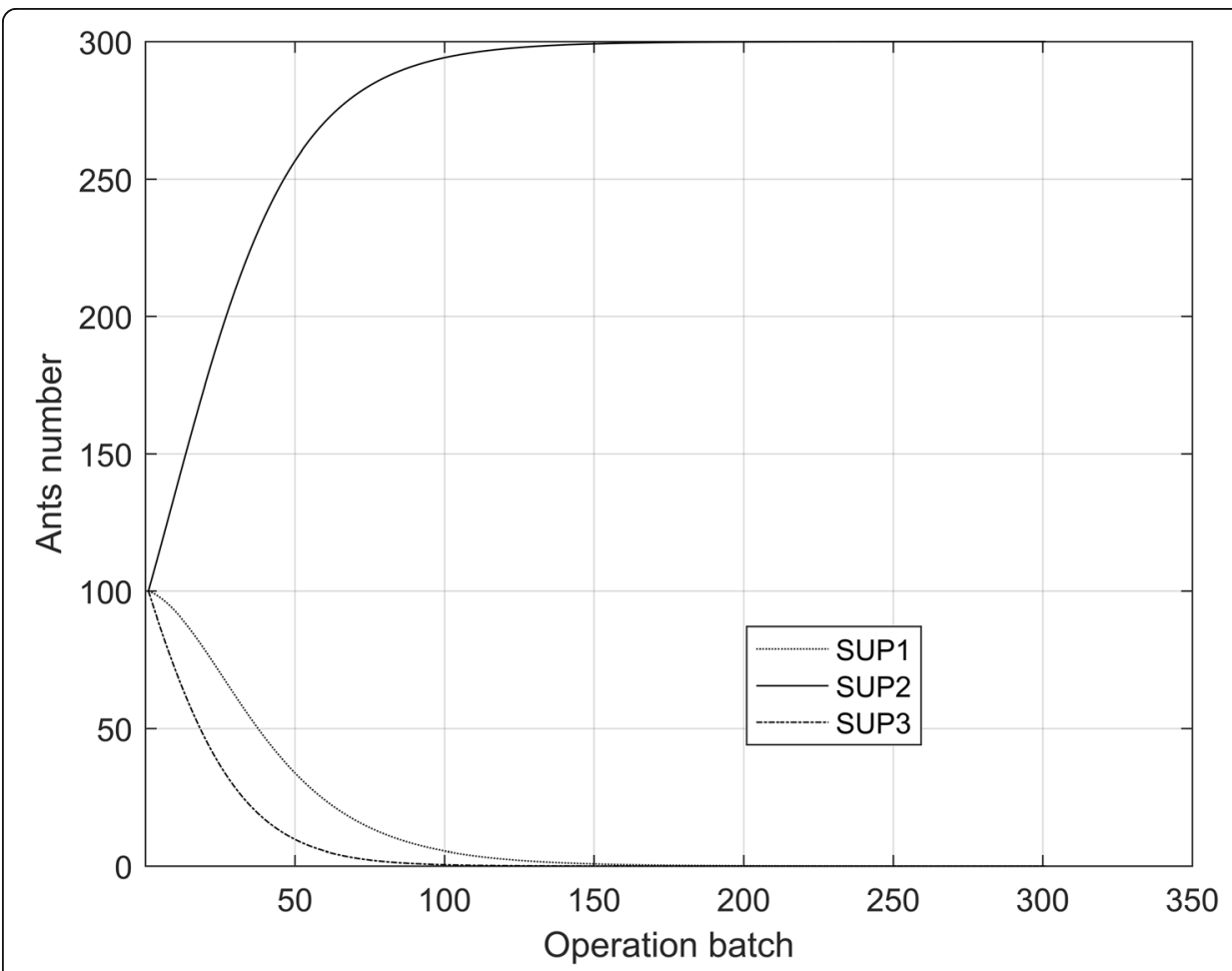

Fig. 5 Convergence results (growth stage) 


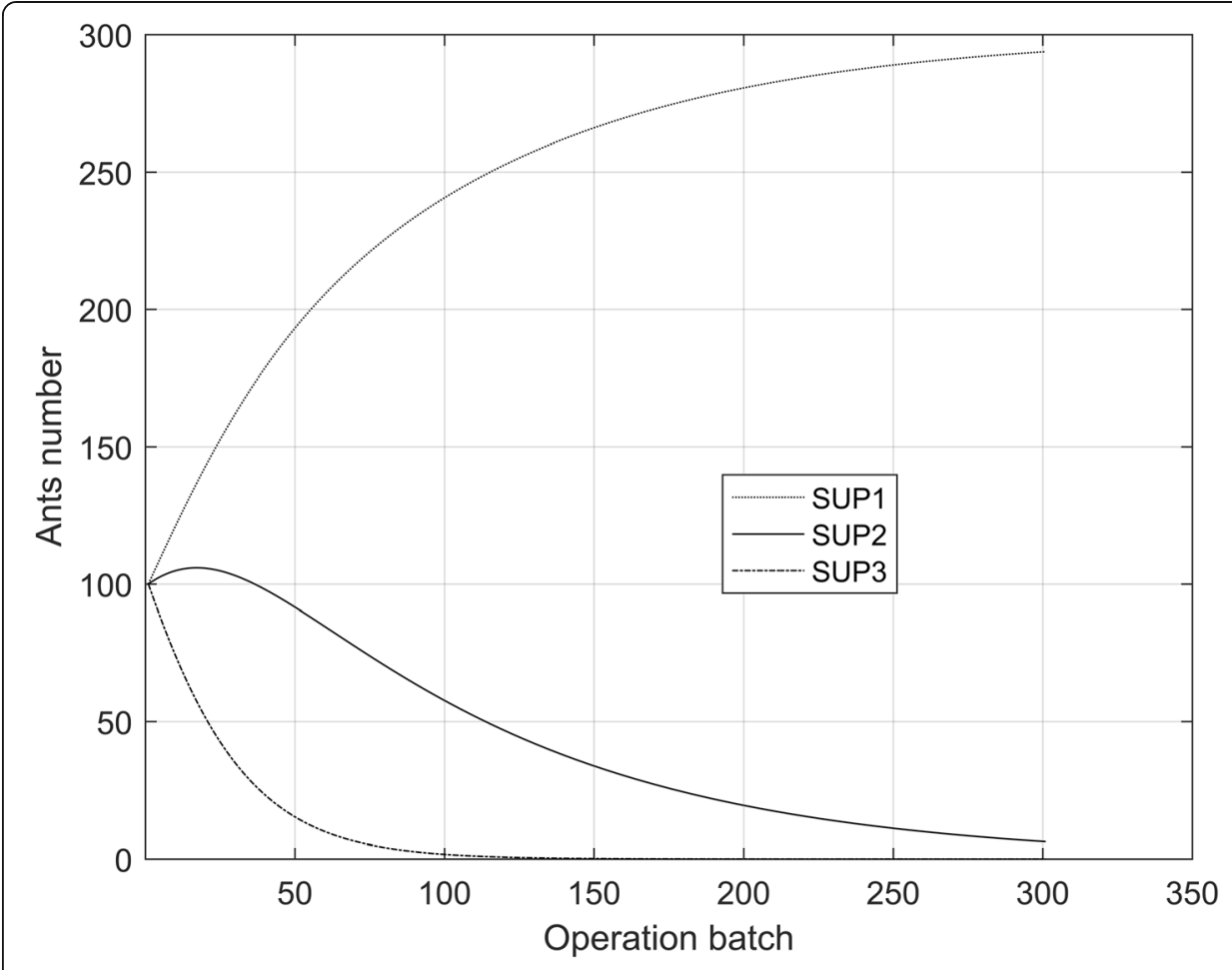

Fig. 6 Convergence results (maturity stage)

proportion of each optimization objectives according to their own strategy and thus achieve their own proper optimization results.

\section{Conclusion}

This paper proposes a feasible approach for resource integration optimization of convenience service platforms under dynamic service modes. Since few studies are devoted to resource integration in dynamic service modes, this study yields a number of contributions to the current literature and practices.

Firstly, the theoretical contributions of this paper mainly lie in the following aspects. On the basis of a systematic literature review, the research gaps are highlighted. Given that few studies consider the influence of different service modes in the process of resource integration, given dynamic service modes, the present research question, how to optimize the integration of service resources under dynamic service modes, is proposed to eliminate the existing gap as much as possible. In addition, the procedure of the proposed method to the problem is straightforward and generally applicable to resource integration optimization problems of the convenience service platforms that adopt dynamic service modes.

Secondly, by combining dynamic service modes, the paper analyzes and explores key factors to be considered in service resource integration. In this way, it provides reference for convenience service platforms to locate key factors that facilitate the integration of service resources.

Thirdly, the proposed method can be used as reference for the resource integration of other products under dynamic service modes. 
Lastly, given the nascent trend of convenience stores transforming into convenience service platforms, relevant literature concerning the optimization of resource integration is still in need. This paper makes a tentative study in this respect, and provides some practices and managerial insights. The approach under dynamic service modes can also be applied to other products.

However, the study has limitations. Its weighing of multiple targets in the optimization model is mainly based on the strategy of the convenience service platforms, and it does not consider the flexibility involved in the convenience service platforms' negotiations with service suppliers. By integrating advanced technologies, like big data and cloud computing, more accurate parameters can be obtained in future research, facilitating the optimization of resource integration.

\section{Authors' contributions}

YY designed the study together with JY. YY drafted the initial manuscript, and the two authors made several rounds of revision together. Both authors read and approved the final manuscript.

\section{Funding}

This work is supported by the Natural Science Foundation of China (No.71872174)

\section{Availability of data and materials}

All data generated or analyzed during this study are included in this published article and its supplementary files.

\section{Ethics approval and consent to participate}

Not applicable.

\section{Consent for publication}

Not applicable.

\section{Competing interests}

The authors declare that they have no competing interests.

Received: 29 November 2019 Accepted: 24 January 2021

Published online: 18 March 2021

\section{References}

Al Hamadi, H. M., Sangeetha, N., \& Sivakumar, B. (2015). Optimal control of service parameter for a perishable inventory system maintained at service facility with impatient customers. Annals of Operations Research, 233(1), 3-23.

Alftan, A., Kaipia, R., Loikkanen, L., \& Spens, K. (2015). Centralized grocery supply chain planning: Improved exception management. International Journal of Physical Distribution \& Logistics Management, 45(3), 237-259.

Ayala, N. F., Frank, A. G., \& Gerstlberger, W. (2019). Managing servitization in product companies: The moderating role of service suppliers. International Journal of Operations and Production Management, 39(1), 43-74.

Bastl, M., Johnson, M., \& Karatzas, A. (2017). Manufacturer-supplier relationships and service performance in service triads. International Journal of Operations \& Production Management, 37(7), 950-969.

Benjaafar, S., Elahi, E., \& Donohue, K. L. (2007). Outsourcing via service competition. Management Science, 53(2), 241-259.

Berry, L. L., Seiders, K., \& Grewal, D. (2002). Understanding service convenience. Journal of Marketing, 66(3), 1-17.

Bolton, R. N., \& Drew, J. H. (1991). A longitudinal analysis of the impact of service changes on customer attitudes. Journal of Marketing, 55(1), 1-9.

Brown, L. G. (1990). Convenience in services marketing. Journal of Services Marketing, 4(1), 53-59.

Canakoglu, E., \& Bilgic, T. (2007). Analysis of a two-stage telecommunication supply chain with technology dependent demand. European Journal of Operational Research, 177(2), 995-1012.

Cao, W., \& Jiang, P. (2013). Modelling on service capability maturity and resource con-figuration for public warehouse product service systems. International Journal of Production Research, 51(6), 1898-1921.

Ching, W. K., Choi, S. M., \& Huang, X. (2011). Inducing high service capacities in outsourcing via penalty and competition. International Journal of Production Research, 49(15-17), 5169-5182.

Colwell, S. R., Aung, M., Kanetkar, V., \& Holden, A. L. (2008). Toward a measure of service convenience: Multiple-item scale development and empirical test. Journal of Services Marketing, 22(2), 160-169.

Dong, J., Wang, G., \& Gao, G. (2007). Multi-supplier selection problem solution based on improved ant colony algorithm. Computer Integrated Manufacturing Systems, 13(8), 1639-1644.

Gahinet, M., \& Cliquet, G. (2018). Proximity and time in convenience store patronage: Kaïros more than chronos. Journal of Retailing \& Consumer Services, 43, 1-9.

Hall, J., \& Porteus, E. (2000). Customer service competition in capacitated systems. Manufacturing \& Service Operations Management, 2(2), 144-165.

Han, S., Ye, Y., Fu, X., \& Chen, Z. (2014). Category role aided market segmentation approach to convenience store chain category management. Decision Support Systems, 57(1), 296-308.

Hasija, S., Pinker, E. J., \& Shumsky, R. A. (2008). Call center outsourcing contracts under information asymmetry. Management Science, 54(4), 793-807. 
Hübner, A., Kuhn, H., \& Wollenburg, J. (2016). Last mile fulfilment and distribution in omni-channel grocery retailing: A strategic planning framework. International Journal of Retail and Distribution Management, 44(3), 228-247.

Kahneman, D., \& Tversky, A. (1979). Prospect theory: An analysis of decisions under risk. Econometrica, 47(March), 263-291.

Lahiri, A., Dewan, R. M., \& Freimer, M. (2013). Pricing of wireless services: Service pricing vs. traffic pricing. Information Systems Research, 24(2), 418-435.

Lamba, K., \& Singh, S. P. (2019). Dynamic supplier selection and lot-sizing problem considering carbon emissions in a big data environment. Echnological Forecasting and Social Change, 144, 573-584.

Liu, W., \& Xie, D. (2013). Quality decision of the logistics service supply chain with service quality guarantee. International Journal of Production Research, 51(5), 1618-1634.

Liu, W., Xie, D., \& Xu, X. (2013). Quality supervision and coordination of logistic service supply chain under multi-period conditions. International Journal of Production Economics, 142(2), 353-361.

Liu, X., Zhang, K., Chen, B., Miao, L., \& Zhou, J. (2018). Analysis of logistics service supply chain for the one belt and one road initiative of China. Transportation Research Part E: Logistics and Transportation Review, 117, 23-39.

Luthra, S., Govindan, K., Kannan, D., Mangla, S. K., \& Garg, C. P. (2017). An integrated framework for sustainable supplier selection and evaluation in supply chains. Journal of Cleaner Production, 140, 1686-1698.

Lyu, G., Chen, L., \& Huo, B. (2019). The impact of logistics platforms and location on logistics resource integration and operational performance. The International Journal of Logistics Management, 30(2), 549-568.

Ma, H., Sun, Q., Gao, Y., \& Gao, Y. (2019). Resource integration, reconfiguration, and sustainable competitive advantages: The differences between traditional and emerging industries. Sustainability, 11(2), 551 .

Merkle, D., Middendorf, M., \& Schmeck, H. (2002). Ant colony optimization for resource-Constrained project scheduling. Evolutionary Computation, 6(4), 333-346.

Oliveira, F. S., Ruiz, C., \& Conejo, A. J. (2013). Contract design and supply chain coordination in the electricity industry. European Journal of Operational Research, 227(3), 527-537.

Oliver, R. L. (1977). Effect of expectation and disconfirmation on postexposure product evaluations: An alternative interpretation. Journal of Applied Psychology, 62(4), 480-486.

Pamucar, D., Chatterjee, K., \& Zavadskas, E. (2019). Assessment of third-party logistics provider using multi-criteria decision making approach based on interval rough numbers. Computers \& Industrial Engineering, 127, 383-407.

Panicker, V. V., Vanga, R., \& Sridharan, R. (2013). Ant colony optimisation algorithm for distribution-Allocation problem in a two-stage supply chain with a fixed transportation charge. International Journal of Production Research, 51(3), 698-717.

Rust, R. T., Inman, J. J., Jia, J., \& Zahorik, A. (1999). What you don't know about customer-perceived quality: The role of customer expectation distributions. Marketing Science, 18(1), 77-92.

Sakashita, N. (2000). An economic analysis of convenience-store location. Urban Studies, 37(3), 471-479.

Shi, M., Zhou, J., \& Jiang, Z. (2019). Consumer heterogeneity and online vs. offline retail spatial competition. Frontiers of Business Research in China, 13(2),231-249.

Szymanski, D. M., \& Henard, D. H. (2001). Customer satisfaction: A meta-analysis of the empirical evidence. Journal of the Academy of Marketing Science, 29(1), 16-35.

Tang, L., Jing, K., \& He, J. (2013). An improved ant colony optimization algorithm for three-tier supply chain scheduling based on networked manufacturing. International Journal of Production Research, 51(13), 3945-3962.

Ting, C. J., \& Chen, C. H. (2013). A multiple ant colony optimization algorithm for the capacitated location routing problem. International Journal of Production Economics, 141(1), 34-44.

Tversky, A., \& Kahneman, D. (1992). Advances in prospect theory: Cumulative representation of uncertainty. Journal of Risk and Uncertainty, 5(4), 297-323.

Wang, Z., \& Li, G. (2019). Research on the evolution logic of the new retail from the perspective of consumption experience. Chinese Journal of Management, 16(3), 333-342.

Wang, Z., Zhu, C., Tian, S., \& Ping, L. (2019). Differentiation and pricing power of online retailers. Frontiers of Business Research in China, 13(1), 101-120.

Wong, T. N., Zhang, S. C., Wang, G., \& Zhang, L. P. (2012). Integrated process planning and scheduling-Multi-agent system with two-stage ant colony optimization algorithm. International Journal of Production Research, 50(21), 6188-6201.

Wood, S., \& Browne, S. (2007). Convenience store location planning and forecasting —A practical research agenda. International Journal of Retail \& Distribution Management, 35(4), 233-255.

Xiao, X., Xiao, D., Lin, J., \& Xiao, Y. (2011). Overview on multi-objective optimization problem research. Application Research of Computers, 28(3), 805-808.

Yao, J., \& Deng, Z. (2015). Scheduling optimization in the mass customization of global producer services. IEEE Transactions on Engineering Management, 62(4), 591-603.

Yao, J. M. (2010). Decision optimization analysis on supply chain resource integration in fourth party logistics. Journal of Manufacturing Systems, 29(4), 121-129.

Yao, J. M. (2013). Scheduling optimization of co-operator selection and task allocation in mass customization supply chain based on collaborative benefits and risks. International Journal of Production Research, 51(8), 2219-2239.

Yao, J. M. (2017). Supply chain resources integration optimization in B2C online shopping. International Journal of Production Research, 55(17), 5079-5094.

Yao, J. M., \& Gu, M. J. (2014). Optimization analysis of supply chain resource allocation in customized online shopping service mode. Mathematical Problems in Engineering, 2015, 1-11.

\section{Publisher's Note}

Springer Nature remains neutral with regard to jurisdictional claims in published maps and institutional affiliations. 